\title{
Dignity and existential concerns among nursing homes residents from the perspective of their relatives
}

\author{
Synnøve Caspari ${ }^{1}$, Vibeke Lohne ${ }^{1}$, Arne Wilhelm Rehnsfeldt ${ }^{2}$, Berit Sæteren ${ }^{1}$, Åshild Sletteb ${ }^{3}$, \\ Anne Kari Tolo Heggestad ${ }^{1}$, Britt Lillestø ${ }^{4}$, Bente Høy ${ }^{5}$, Mai-Britt Råholm ${ }^{6}$, Lillemor Lindwall ${ }^{7}$, \\ Trygve Aasgaard ${ }^{1}$, Dagfinn Nåden ${ }^{1}$
}

1. Oslo and Akershus University College of Applied Sciences, Norway. 2. Stord-Haugesund University College, Faculty of Health Education, Norway. 3. University of Agder, Faculty of Health Sciences, Norway. 4. University of Nordland, Norway. 5. VIA University College, Aarhus, Denmark. 6. Sogn og Fjordane University College, Norway. 7. University of Karlstad, Sweden.

Correspondence: Synnøve Caspari. Address: Oslo and Akershus University College of Applied Sciences, Department of Nursing, Box 4, St. Olavs plass, NO-0130 Oslo. Email: Synnove.Caspari@senior.hioa.no

Received: February 7, 2014

Accepted: April 17, 2014

Online Published: April 27, 2014

DOI : $10.5430 /$ cns.v2n3p22

URL: http://dx.doi.org/10.5430/cns.v2n3p22

\section{Abstract}

Aims and objectives: The aim of this cross-country Scandinavian study was to explore how residents in nursing homes experience that their dignity is promoted and attended to. This is one part of the Scandinavian project in which we interviewed residents, relatives and staff members.

Background: The main subject concerns the dignity of residents of nursing homes for older people. This article brings forward results from interviews of relatives on how they experience that the dignity is met, promoted and attended to for their next of kin.

Design: The study was qualitative with a hermeneutic approach.

Methods: Qualitative research interviews of 28 relatives of residents at six participating nursing homes in Scandinavia. The results derive from analysis of the interviews using Kvale's three levels of interpretation; self-understanding, common sense and a theoretical understanding.

Results: The following themes emerged, from the perspective of the relatives, concerning what was deemed important to the resident according his existential needs and concerns: a). To have a comfortable, homely and practical room. b). To have close contact with family, friends and with the staff. c). To have aesthetic needs and concerns attended to. d). To have ethical needs and intrinsic values attended to. e). To have cultural and spiritual needs and concerns attended to.

Conclusion: The results provide more substance to the theme and are all important in terms of the residents' feeling of worthiness and dignity. In general it seemed that the relatives experienced a positive encounter with the staff, but it was also mentioned that staff members were not confronted about episodes that were undignified and disgraceful. This could be a sign or expression that they were worried that negative responses or complaints could lead to a kind of reprisal against the resident and to indignity. 


\section{Key words}

Existential concerns, Relatives, Residents, Nursing homes

\section{I ntroduction}

As the life expectancy increases in Western populations and the individual human being frequently has to spend his or her late and final years in institutions, it is important that these institutions are attractive and function as a good home for the residents. The main theme in this article is about the residents' dignity. Furthermore, as an important part of promoting and taking care of the residents dignity, attempts are made to ascertain how attention is given to the existential needs and concerns experienced by relatives to be important to their resident kin.

Edlund ${ }^{[1]}$ states that dignity is based on a source of values and is expressed as absolute dignity and relative dignity. The human being is seen as an entity of body, spirit and soul, who in the process of creation was given freedom and responsibility as well as an absolute human value. The absolute dignity contains values like holiness and human worth and cannot be violated or taken away, but man also has a relative dignity as a part of the human being's psychical and bodily dimension. This is a dignity constituted by social and cultural influences and source of values experienced through life. Relative dignity can be harmed, infringed or violated, for instance by neglect of existential needs or concerns, but relative dignity can also be restored.

It might be a serious step for the older person when he has to leave his home to admit that he is not capable of taking care of himself anymore and that his future home is to be, most often, a small room at an institution. To the relatives it might be a difficult decision to make when they transfer their relative to an institution. They may ask themselves if they made the right decision. They may wonder if it is the best solution for the resident to stay at an institution. If the resident has a next of kin who is concerned and maybe loves him/her, practical questions arise, such as: does he get enough food, drink, medicines and do they preserve and promote his dignity?

Most commonly one speaks of existential needs and concerns and relates the theme to spiritual or/and religious questions, but in terms of the needs of a resident in a nursing home, the basic needs are very relevant and are associated with whether he feels respected or not, confirmed as a human being. To be confirmed is important for both the young and the elderly ${ }^{[2]}$, it is a human need to feel that one's life still has meaning and that one's dignity is respected. Existential needs relate to all aspects of life, to physiological, ethical, aesthetic, psychical, social and spiritual concerns ${ }^{[3]}$.

Existential concerns and needs that older residents of nursing homes might have, are wide in scope. Our pre-understanding is that their relatives try to help, limit and fulfil their loved ones' needs in order to make the best of the situation, and their goal is to contribute to the quality of life and to promote and preserve the dignity of their residents.

In this present article, the existential needs and concerns of the residents in nursing homes will be related to their dignity, because if the existential concerns and/or needs are neglected, eldercare will be insufficient and their life in general will become undignified. Mostly it will be the last home for the resident and the end of 'his or her road'. This can be felt as an existential pain, a physical and spiritual suffering. The residents will be more or less dependent on help from others on the practical, cultural, social and spiritual field. If the resident is clear minded, he might perceive being institutionalized as a defeat, whereas others might find it to be a relief.

Theoretical and empirical studies have been carried out to explore the concept of dignity and existential needs ${ }^{[1,4-6]}$.

Existential needs and concerns in accordance with the resident's dignity (residents in Nursing Homes) yielded some articles and projects related to different topics that are relevant and supplementary to the main theme of 'dignity in nursing homes' in this article. 
Existential needs or concerns derive from the word 'to exist', which ontologically means to live, to be alive, to have a soul, to belong, to be vital, to be awake, and to breathe - that is, to be. Existential needs and concerns can be related to all aspects of life, practical, social, pecuniary, aesthetic, ethical and familiar considerations. Existential needs and concerns also involve the mental field as well as intellectual and spiritual questions ${ }^{[7]}$.

The existential being in this article relates to the residents' daily life at the nursing home. This aspect is found in literature to involve both practical and spiritual concerns. Gormally ${ }^{[4]}$ claims, in the Linacre lecture he gave on Pope John Paul II's teaching on existential dignity in July 2003, that existential dignity is the dignity we may possess in virtue of living well. He refers to St. Thomas who says that in realizing what is good in their lives, human beings achieve existential dignity. These "goods" constitute the basic ingredients of our fulfilment as human beings. Wong ${ }^{[8]}$ mentions that it is common to speak about physical health and physical activities without mentioning spiritual and existential dimensions. Four major psychological processes for living a good life, according to Wong \& Fry ${ }^{[6]}$, are: motivational (purpose, life goals, needs), cognitive (understanding, making sense of life), social/moral (responsibility, accountability, commitment), and affective (enjoyment/evaluation, positive emotions). Wong \& Fry ${ }^{[6]}$ define successful ageing as a relatively high level of physical health and psychological wellbeing. Rowe and Kahn ${ }^{[5]}$ define successful ageing as the ability to maintain a low risk of disease-related disability, to have high mental and physical functions and an active engagement in life - by this they mean happy activities such as relating to others and continuing productive activities.

According to Fromm ${ }^{[9]}$ people are alike in the sense that they share existential needs and concerns. Existential needs and concerns must be met if life is to be meaningful and important for the human being. Regarding residents at nursing homes, primarily old people, we find that these five existential needs that Fromm emphasizes are relevant: 1). Relatedness relationships with others, care, respect, knowledge; 2). Transcendence - creativity, develop a loving and interesting life; 3). Rootedness - feeling of belonging, both socially and in the environment; 4). Sense of identity - see ourselves as a unique person and part of a social group; 5). A frame of orientation - the need to understand the world and our place in it. These needs are important because every person needs physical and mental stimulation and variation. These needs might be superior in general through life but as people get older, the needs most often will be on a different scale than in earlier and more active years ${ }^{[9]}$.

Dweyer, Nordenfeldt \& Ternestedt ${ }^{[10]}$ found that sources of meaning were created by having a sense of: physical capability, cognitive capability, being needed and belonging. Meaning was created through an inner dialogue, by communication and by relationship with others.

Psychiatrist Irvin D. Yalom writes about existential concerns that have always occupied human beings. In his classic text, Yalom ${ }^{[11]}$ outlines what he considers to be the four ultimate concerns of humankind: 1) Death, 2) Isolation, 3) Meaningless, and 4) Freedom. As a psychotherapist, Yalom was primarily interested in how these existential concerns informed the therapeutic process. He believed that our psychological difficulties stem from an inability to reconcile ourselves with these existential concerns. In order to feel better, then, we need to make peace with these concerns.

The resident may feel abandoned and lonely ${ }^{[12]}$. Nilsson ${ }^{[13]}$ states that to live involve belonging in the world. Even if the institution has many residents, the individual resident may feel that he is alone among strangers.

Existential distress refers to a mental pain caused by the loss of normal roles. Maybe the feeling of loss of dignity and loneliness in addition, gives rise to a feeling of distress. Existential loneliness has become a topic in the literature and is understood as an intolerable emptiness, sadness and longing that results from the awareness of one's fundamental separateness of human being ${ }^{[14]}$.

Report results from a study on how to preserve the dignity in caring for older adults showing the importance of nursing documentation ${ }^{[15]}$. From a rehabilitation context Caspari, Aasgaard, Lohne, Slettebø \& Nåden ${ }^{[16]}$ report perspectives on 
how to preserve and promote the dignity of patients, where the patient should be seen as an active agent, respected, included and listened to, and free to make critical comments.

Baillie ${ }^{[17]}$ presents the meaning of patient dignity, how patients' dignity is threatened and how it is promoted, with a particular focus on the effect of staff behavior. Polzer Casarez \& Engebretsen ${ }^{[18]}$ illuminate how existential needs and spiritual needs are connected with health care ethics and the individual's mental health and well-being.

We know that it is vital that the existential needs and concerns of the residents in nursing homes are promoted and attended to. In this investigation five points emerged that may have great consequences if they are neglected; they concerns the residents' dignity, the feeling of being worthy.

\section{Aim of the study}

Dignity is the main subject of this cross-country Scandinavian study, and the goal was to gain knowledge on how dignity is preserved and attended to for the residents living in nursing homes. Since existential needs and concerns are an important and even vital aspect for the residents' wellbeing, we found it valuable to interview relatives and nursing home staff members, in addition to the residents. Through the use of three different points of view, it was thought that we would get a broader angle of approach and valuable data.

\section{Method}

\subsection{Design}

The study has a descriptive and explorative design inspired by Gadamer's ${ }^{[19]}$ hermeneutics, and is part of a larger project concerning how the dignity of residents is promoted and maintained when they live in a nursing home. Gadamer's aim is not to propose a method, but rather to describe what occurs when understanding takes place.

Following Kant's critique of the condition of our knowledge, Gadamer traces a philosophical question in human sciences and in experience as lived, that is, how is understanding possible? He turns to an old insight according to which the manner in which a text is understood has three dimensions: understanding (intelligere), interpretation (explicare), and application (applicare) ${ }^{[19]}$.

Accordingly, the concept of understanding reaches its climax in application, which concludes the fusion of horizons. Horizon is not a rigid boundary but something that moves with one and invites one to advance further. Horizon is the range of vision that includes everything that can be seen from a particular vantage point. In this analysis, the horizon will be the knowledge the researcher has from literature and articles, as well as the suppositions and prior experiences of the interpreters of texts. To have a horizon means not being limited to what is nearby but being able to see beyond it. By analysing the text, a new horizon develops as the horizons (the new and the 'old' knowledge) melt together ${ }^{[19]}$.

The researchers' pre-understanding was developed through interviews with residents before the interviews of relatives and through literature and research on the subject. The five existential needs that Fromm emphasizes as relevant were given more concise content and the pre-understanding was incorporated in the new horizon that emerged through the five points that the relatives emphasized.

\subsection{Setting and participants}

Six Scandinavian nursing homes participated. About 80 percent of the residents living in nursing homes are suffering to various degrees from dementia ${ }^{[20]}$, and therefore we found that the staff members were the most capable to make the choice as to whether or not to participate in the study. Furthermore, it was found valuable to get information from the relatives on how they experienced the care of their next of kin. They might have different opinions, experiences and maybe 
interpret situations and events in a different way than their next of kin. The relatives were selected and contacted by the staffs and they were informed about the project. All the relatives were given information pertaining to the project. Twenty-eight relatives were interviewed, Male (11), Female (17). Relation: Daughters 14, age 47 - 67, Sons 4, age 49 65, Husbands 6, age $61-89$, Wife 1, age 76, Sister 1, age 79, Cousin 1, age 71, Son in law 1, age 53 . The interviews were conducted by nine researchers from the project group. The interviews were conducted at the nursing homes. Neither residents nor any staff members were present at the interviews.

\subsection{Method of data collection}

The interviews followed an interview guide with open-ended questions with a view to gathering as rich data as possible, but it was also preferred that the informants spoke freely on the subject, to take into account their thoughts and reflections. The interviews were tape-recorded and transcribed verbatim by an external office. The interviews were performed at the respective institutions on a one-to-one basis. The duration of interviews was about forty-five minutes to one hour. The focus of the interviews was on relatives' encounters with the nursing home and the staff and how they experienced that the patient's dignity was attended to and promoted. The interview guide raised the following questions: Demographic data: Age, gender, profession, relation? For how long have you had a relative at the nursing home? How did you experience the encounter with the nursing home and with the staff members? How do you experience visits to the nursing home? Do you think the relationship between you and your next of kin has changed? What is it that makes your next of kin's experience of living at the nursing home positive or negative? How do you experience the meetings with the staff members? Is there anything in the encounters that you wish would be different? How do you experience the care that is given through daytime, evenings and nights? What do you think about the cultural activities offered: Is there anything that you appreciate or value especially highly? What importance do you think these activities have for you or for your next of kin? What does the concept of dignity mean to you? Is it a word that you are concerned about? Can you give an example of your next of kin being met with dignity? Can you give an example of your next of kin being met with indignity? Do you have anything to add that we didn't mention through this conversation?

\subsection{Method of data analysis}

The interviews were read and analysed according to Kvale's ${ }^{[21]}$ three levels of interpretation; self-understanding, common sense and a theoretical understanding. The first step in reading the interviews was to sort out what exactly was said and talked about, subjects and themes, and then by the next step to interpret these statements and utterances on a common sense level. This second level can be more informative than the first level as it is condensed to the main subject of the utterance. On the third level the aim was to discuss the results from all the interviews (relatives) in the light of literature and scientific studies on the topic. When results emerged, the whole team worked together on the different themes that were sorted out from the interviews. The members of the project group individually gave their comments and suggestions concerning the results. Furthermore, a matrix was used which allowed the emergent themes to be classified. Then we went back to the interviews once more to find what was said according these themes. Quotes from these statements are presented.

\subsection{Ethical considerations}

Before the study started, it was approved by the regional ethics committee in Norway and it was authorized in compliance with the privacy protection of Norwegian Social Science Data Services (NSD) and by the respective ethical agencies in the other participating countries. The participants received information both in writing and verbally. Participation was voluntary and participants could withdraw at any time without giving a reason. The interviews were confidential and the collected data were depersonalized. A written declaration of consent to participate was signed by each participant.

The participants could also ask questions during the interviews. Anonymity and confidentiality were respected throughout the research period and publication of findings. 
To avoid the interviewers' own feelings and values influencing the relatives being interviewed, the interview guide was an asset. The interview guide was worked out by nearly all members of the project group. The questions asked were as neutral as possible in terms of the interviewers' (researchers') own role, feelings and values.

\section{Results}

The relatives revealed both their own experiences when they first encountered the nursing home and, further, their impression of how their next of kin perceived that his/her existential needs and concerns were attended to and promoted.

Mostly the relatives had experienced their initial encounter with the nursing homes as positive. They felt that they were welcome and that they were listened to in relation to their residents' wishes and needs. However, it was also reported that certain undignified and disgraceful incidents occurred.

When the resident had obtained a room at an institution, the relatives often experienced relief and a feeling that they could now relax and feel confident that their next of kin was well looked after, that his daily needs and concerns were attended to and that the resident understood why he had to stay at a nursing home.

The following themes emerged, from the perspective of the relatives, on what was important to the resident in terms of his existential needs and concerns:

a) To have a comfortable, homely and practical room.

b) To have close contact with family, friends and with the staff.

c) To have the aesthetical needs and concerns attended to.

d) To have intrinsic values attended to.

e) To have cultural and spiritual needs and concerns attended to.

To the relatives, it was often a relief to unload the burden they had carried for maybe a long time, for example the worry and apprehension that something might happen when their loved one was alone. Now they thought that they could be sure that he was safe, that he was attended to and that he got the help he needed.

\subsection{To have a comfortable, homely and practical room}

The value of having a room of their own was emphasized. One relative put it this way: "She was also placed in a room together with another woman and even though there is a curtain between them, she still feels that there is another person in the room”. It was preferred to have a room with a private bathroom, a room with their personal furniture and belongings which could help them to experience and feel rootedness. Rootedness refers to the need to establish roots or to feel at home in the world. The resident might feel that a bit of their former home has been moved to the institution, their new home. To be forced to share their room with a stranger day and night, could be, and mostly was, experienced as straining. Problems would often arise concerning daily procedures like when they wanted to go to bed, to keep the lights on or not, to have an open window or not, as examples. Some of the residents had experienced that the roommate was very ill and dying. When death was near, the resident frequently had to leave the room, which was an extra existential burden as it was upsetting. One resident had experienced sharing the room for five years with other residents. During these years the other residents had died in turn, and this was experienced not only once, but five times in succession. The resident had to move out of the room to give the dying person peace and quietness. The resident was also moved out to be spared the stress, and she felt that she was homeless, that the room was only temporary. Another relative said: "The room means a lot but the hygiene could have been better. The aesthetic aspect is connected with dignity.” 
To feel at home in your own home, to experience that your dignity and integrity are respected, it is important that your daily needs are attended to in accordance with your own decisions, that you can feel safe and comfortable.

"To have a nice room is important both for the resident and for the staff. If the environment gets run down and threadbare, both the staff members and the patients are influenced", one of the relatives said.

The relatives mentioned the residents' room and facilities, with their personal belongings such as paintings and pictures, furniture, books, TV, things that could make them feel at home, feel that they had brought along a piece of their home, as mentioned before. "We have decorated as best we could", one relative said. "My mother's room needs to be painted, but it says in the papers that we cannot do that”. In general the aesthetics mentioned mostly concerned the residents' private room and other facilities at the institution. Some of the rooms needed renovating, but the most important thing for the residents was to have a room of their own.

\subsection{To have close contact with family, friends and with the staff}

To have close contact with their family and friends was important so that residents did not feel banished. The ways the patients adapted to the new situation varied. To the relatives it was encouraging if the patient seemed to be relaxed and satisfied. One resident was said to have uttered to the relative that: "It is ok here but I am depressed, I think it is stupid that I am here and not at home, but I have to say that it is ok." It was important that they did not feel that they were forgotten, banished, that they just were placed 'out of the way'. It was positive if they were visited by family members or friends - if they had any, to feel that they still were loved and wanted. This relates with the need of feeling related.

Another relative said: "My mother has spent a long time adjusting to this home and accepting - accepting, in a way -the situation”.

In some homes, the staff members were very attentive. The residents were welcomed back if they had been out on visits and furthermore, they were talked to and treated as highly regarded adults, with respect and dignity. The need to preserve identity and integrity meant a lot to old persons. If they were treated or talked to in an infantile way, it was perceived as degrading. "My mother does not say anything, she just gets very sad". It was emphasized that the attitude of the staff was very important concerning how they experienced their dignity. Residents might feel humiliated if they were 'overlooked' perhaps due to reduced sight or hearing ability. "It is much easier to talk with me and neglect the resident", a relative said.

Another relative stated: "I think that I am very important to my mother and also concerning how she gets attended to. I think you have to be careful about having too many or too high expectations, but as a next of kin I can talk to the staff about some problems, if I do it in a nice way”.

One relative said: "Sometimes we experience that my mother is not seen nor heard, she is overlooked or neglected".

\subsection{To have aesthetical needs and concerns attended to}

One relative emphasized the aesthetic area and said: "Yes, aesthetics means a lot, both for the residents and also for the staff. The attitudes may otherwise get a bit shabby" she said. The aesthetic area concerned hygiene, the fact that the resident could have a shower or daily wash, and that the environment was clean and tidy. Further the aesthetical needs that the patients mentioned included the importance of getting help, if needed, to be well-dressed, proper and representable according their wishes. One relative said: "It could be kept cleaner here". Their personal aesthetics was related to being nicely dressed with clothes that were suitable, good-looking and harmonic. Another relative said: "The patients are very concerned with looking their best, that their hair, for instance, is nicely combed and attended to". "My mother feels that she is forgotten sometimes. For instance when all the others have been to the hairdresser and she is sitting in a corner, omitted". Furthermore, they felt more valued and dignified when they got some help with make-up and care for hands and feet. One resident had a positive experience. The relative told: "My mother likes to feel nice and here they attend to that. 
They dress her nicely with jewellery and they curl her hair”. Another relative said about her mother: "This is important in one's old age, to be dressed nicely with jewels and in a way 'smartened up'. She is happy that they have a hairdresser on the same floor".

One relative said: "The aesthetic area has something to do with how you experience being at a place. If it is new and nice, not worn, it concerns the attitude both for the resident and the staff members”.

\subsection{To have intrinsic values attended to}

The residents' autonomy and intrinsic value - the feeling that he was respected and regarded as a dignified person was one ethical concern. If you cannot decide when you want to go to bed, but you have to follow the routines at the institution, if you want to keep the light on, and it is turned off, if you cannot get up when you feel like it in the morning, or which dress you would like to wear, then your autonomy and integrity are not respected; these things might make you feel undignified. To be autonomous also has another aspect. It is not always in the residents' best interest to expect him to decide and choose all the time. The resident might be tired and does not want to be asked on all occasions. "My mother was clear and they said to her all the time: You decide. My mother died a little each time they said that”. She wanted to delegate some of the decisions that were not considered important to her.

"Problems arise when the staffs do not speak the Norwegian language and this can lead to undignified situations, especially if the patient has a hearing problem," one relative said.

The relatives revealed that they often had lived with constant worry and a feeling of insecurity for their loved ones, sometimes for many years. It appeared that it was hard sometimes to get a room at a nursing home, especially if they had preferences about which nursing home to stay at.

The level of health service they were given meanwhile was insufficient and often provided by incompetent personnel. The 'home service' staff was more or less uneducated; they did not have the time required; almost every day different people came to attend to them, and the resident never knew who was coming to help him or what time of day he would be attended to.

In general, it was felt to be a relief if the relatives were able to feel confident that the resident was well looked after and that he got his medications on time. Still they were constantly worried if they suspected that he was neglected in any way, that he was not listened to or respected. In some cases the resident did not understand why he could not leave and go back to his private home and this could be an extra burden for the resident according to the family member. The relatives wanted to be consulted and listened to by the staff when they had suggestions or complaints. Often they visited their loved ones in the evening and that could make it problematic to meet the primary nurse who provided care for their resident. Information could be a problem, but often it was said that they thought the staff knew the best solution if they had questions, problems or decisions to be made.

Relatives often missed having a regular dialog with the primary nurse, if the resident had one.

If they did not trust the staff, it was important to be consulted. For some relatives it was an extra burden that they had to be aware of the daily needs - suitable clothing, enough food, enough to drink, that the resident got the help when needed, for instance to go to the toilet or go to bed when he wanted.

\subsection{To have cultural and spiritual needs and concerns attended to}

Family members did not mention explicitly or talk about their resident's spiritual needs or concerns. It was said that some residents, who had a religious faith and who wanted to listen to religious songs and hymns, were not offered an opportunity to do so. In terms of one resident in particular, the relatives said they had been asked to suggest songs and music that the 
resident was fond of. They worked out a list and gave it to the staff. The list was hung on the wall but that was it. The resident had told the relative: "When they saw the songs were religious tunes and hymns that she liked, the result was that no songs, psalms or music were procured”. Those who did not want to listen to a religious service were protected or shielded from religious activities by a closed door. One relative said: “it is important that you don't have too many high expectations".

\section{Discussion}

The purpose of this article was to present results on how existential needs and concerns were attended to at nursing homes from the perspective of family members. The article refers to the residents' opinions indirectly and as apprehended by their next of kin. The existential concerns and needs as referred to in this article are components that are significant for the individual human beings' dignity and worthiness. One's individual being in the world as one important chain in the 'chain of life' also gives your being or existence an innate dignity.

The residents' ability to adapt to the new situation, to their new home and surroundings, varied. An investigation by Wikström ${ }^{[22]}$ showed that 26 per cent of the residents at nursing home centres adapted well, 43 per cent accepted the situation and 31 per cent did not adapt or adapted poorly.

In our study we found that the existential concerns and needs were maintained and promoted for some residents at the nursing homes. On the contrary, others experienced that existential concerns and needs were neglected. For instance, when one experience that one's home has to be shared with a stranger, and one has to leave one's home because another person is dying in the other bed, this is not dignifying; it is not living well. In such a situation thoughts of death become even more relevant, Yalom says ${ }^{[11]}$.

If we follow Kant's universal law, one can never make it a general maxim to allow others to be mistreated. Gormally ${ }^{[4]}$ says that existential dignity is the dignity we may possess in virtue of living well. He refers to St. Thomas who says that in realizing what is good in their lives, human beings achieve existential dignity. Existential dignity is acquired precisely by living well as a human being. This is one example of how one can be deprived of dignity.

One important theme of this study was the ethical considerations concerning how the residents were met and respected by the staff. According to Gallagher ${ }^{[23]}$, respect and dignity are two values that appear to be inextricably linked. The residents experienced being talked to in a neglectful or even humiliating way. For instance, when they uttered a wish to postpone bed time, they could be told that they had to go to bed but didn't need to go to sleep. This can be said to be a violation of patients' dignity and an example of the resident's autonomy and integrity not being respected. In such situations, the residents' relative dignity ${ }^{[1]}$ is not attended to. The freedom ${ }^{[11]}$ of accepting the situations that may occur and the feeling that they are worthy of the needed help, and that they are listened to, might give a 'boost' to their feeling of dignity.

There was a big difference between those staff members who had been educated and those who had not, and the relatives had the opinion that education led to higher and broader understanding and that the reasons for incidents like those cited above could have been avoided if the staff in general had been more competent and trained.

Human beings have a need to be stimulated, both in a physical and psychological (mental) sense; in this context it means stimulation of residents in nursing homes, and here the relatives and friends are important links to the outside world. This helps to keep the natural ties intact and to reduce the feeling of isolation and meaninglessness ${ }^{[1]}$. Fromm ${ }^{[9]}$ calls this rootedness.

The opportunity to socialize and meet other people is perhaps positive when one lives in an institution like a nursing home, but primarily according your own wish to socialize ${ }^{[9]}$. It is important that you can withdraw when you feel like it. The 
demands seemed to be vary greatly according their expectations. If you are happy just to have a room at an institution, whatever it looks like, and no connection with the outer world, then you might have very small expectations. Some of the relatives tried to make the best of the facilities and the residents were thankful if they got help with their daily needs, hygiene, hair, makeup and nails and were properly dressed. This is in accordance with findings by Caspari ${ }^{[24]}$, and Ulrich $[25,26]$.

In terms of the daily needs, some relatives were worried that the patient did not get enough to eat and drink. In some cases it was underlined that the patient did not have proper clothing. Some of the residents experienced that they were not asked, when getting dressed, what they wanted to wear. Moreover, one resident had said that he had to wear long woollen underwear on a warm summer day and another that she got a light thin 'short sleeve' nightgown on a cold winter's night. This made the residents feel humiliated and belittled and made the relatives worry. The residents did not feel esteemed if they had no privacy, nowhere to withdraw to be on their own. Mostly the residents seemed to be very modest, thankful and humble.

Spiritual questions might become relevant for some of the residents - subjects that might raise common questions and thoughts, religious or spiritual ${ }^{[11]}$. Thoughts on death were not mentioned and the existential loneliness that the resident might feel was mitigated by trying to keep contact with family and friends. To get old, fragile and in need of help to manage your daily activities might be felt as a burden in itself and freedom as limited. To feel free, it is important to have integrity and autonomy ${ }^{[27]}$, to be treated with respect and to feel that life still has meaning ${ }^{[8]}$. Sources of meaning as measured by Wong \& Fry ${ }^{[6]}$ are related to both presence of well-being and absence of mental illness. Meaning in life can refer both to situational meaning and to existential meaning. Existential concerns were hardly mentioned by the relatives. At a conference in Toronto in 2008 where the human question for meaning was the main subject, the same question as King David (Psalm 142, verse 1-5) ${ }^{[28]}$ asked three thousand years ago was raised: "Why does not anyone ask me about my soul”? It might be that the resident's silence is often interpreted as if he has no need for this kind of conversation.

\section{Methodological considerations}

It might be seen as a limitation that all the participants had a Scandinavian background and that the study took place in Scandinavian nursing homes. Further it might be a limitation that the researchers are Scandinavian with the same background as the residents and also in this case, as the relatives. The credibility criteria were established as the results of this qualitative research interviews were transcribed by an external office. The interviews were analyzed by the twelve researchers in the project group who tried to get the participants view on the phenomena/theme. The participants are the only ones who can legitimately judge the credibility of the results but it was considered that the results should be presented when the project was concluded. The transferability of the results from this study should be of great value to all nursing homes, not only to those participating in the project.

\section{Conclusion}

In this study we found that there were mostly positive, but also some negative, experiences related by the relatives concerning the residents' dignity and existential concerns. The interpretation of the interviews led to a broader understanding concerning the topic. Undignified and stressful situations that the residents might experience are areas where improvements can be made. The residents are in a vulnerable situation and the relatives are the link between their former and their present situation. The relatives often tried to do as best they could, but it was also mentioned that one should not have too great expectations.

This article has focused on and emphasized themes that one should think were a matter of course or to be taken for granted, but it seems that it is necessary to underline and call attention to the importance for the elderly of the results that emerged. To experience that the dignity of the resident is maintained and promoted confirms their worthiness even as old, fragile and dependent persons. 
The relatives generally experienced relief when their loved one got a room at a nursing home, if the resident was well attended to, if he seemed to be comfortable and if he accepted and adjusted well to the situation. Some relatives could experience an unhappy period if they observed that their family member was offended and not treated with dignity.

In general it seemed that the relatives experienced a positive encounter with the staff, but it was also mentioned that staff members were not confronted about episodes that were disgraceful. This could be a sign or expression that they were worried that negative responses or complaints could lead to a kind of reprisal against the resident.

\section{Acknowledgements}

The authors want to thank the participants for sharing their experiences.

\section{Funding}

This work was supported by the Norwegian Research Council [grant number 190889].

\section{References}

[1] Edlund M. Människans värdighet - ett grundbegrepp inom vårdvetenskapen (Human dignity - a basic caring science concept). Dissertation. Åbo: Åbo Akademi University Press; 2002.

[2] Nåden D, Sæteren B. Cancer patients’ perception of being or not being confirmed. Nursing Ethics. 2006; 13: 222-235. PMid:16711182 http://dx.doi.org/10.1191/0969733006ne873oa

[3] Helminiak D. Spiritual concerns, Erich Fromm's Existential needs and concerns. Journal of Psychology \& Theology. 1988; 16: 222-232.

[4] Gormally L. On Human Dignity and Bioethics, Part 1. Zenit Organisation, ZEO3071022, 10, Linacre Lecture on Pope John Paul II’s Teaching on Existential Dignity; 2003.

[5] Rowe J, Kahn R. Model of successful aging. Gerontologist. 2002; 42: 613-20.

[6] Wong PTP, Fry PS. The human quest for meaning. Journal of Adult Development. 1998; 7: 187-188.

[7] Marc-Wogau K. Filosofisk leksikon (Philosophical dictionary). Stockholm: Fabritius \& Sønners forlag; 1969.

[8] Wong PTP. Meaning of Life and Meaning in Death in Successful Aging. 2012. Available from: http://www.meaning.ca/articles/successful_aging.html

[9] Fromm E. At have eller at være (To have or to be). Copenhagen: Gad; 1982.

[10] Dwyer LL, Nordenfelt L, Ternestedt B-M. Three nursing home residents speak about meaning at the end of life. Nursing Ethics. 2008; 15: 97-109. PMid:18096585 http://dx.doi.org/10.1177/0969733007083938

[11] Yalom I. Eksistensiell psykoterapi (Existential psychotherapy). Translated to Norwegian by M. Solli. Oslo: Arneberg forlag; 2011.

[12] Nåden D, Rehnsfeldt A, Råholm M-B, Lindwall L, Caspari S, Aasgaard T, Slettebø Å, Sæteren B, Høy B, Lillestø B, Heggestad A-K, Lohne V. Aspects of indignity in nursing home residences as experienced by family caregivers. Nursing Ethics. 2013; 20: 748-761. PMid:23462504 http://dx.doi.org/10.1177/0969733012475253

[13] Nilsson B. Savnets tone i ensomhetens melodi (The tune of want in the loneliness melody). Dissertation. Åbo: Åbo Akademi University Press; 2004.

[14] Ettema E, Derksen LD, van Leeuwen E. Existential loneliness and end of-lifecare: a systematic review. Theoretical Medicine Bioethic. 2010; 31: 141-169. PMid:20440564 http://dx.doi.org/10.1007/s11017-010-9141-1

[15] Anderberg P, Lepp M, Berglund, AL, Segesten K. Preserving dignity in caring for older adults: a concept analysis. Journal of Advanced Nursing. 2007; 59: 635-43. PMid:17727405 http://dx.doi.org/10.1111/j.1365-2648.2007.04375.x

[16] Caspari S, Aasgaard T, Lohne V, Slettebø, Å, Nåden D. Perspectives of health personnel on how to preserve and promote the patients’ dignity in a rehabilitation context. Journal of Clinical Nursing. 2013; 22: 2318-2326. PMid:23651360 http://dx.doi.org/10.1111/jocn.12181

[17] Baillie L. The impact of staff behavior on patient dignity in acute hospitals. Nursing Times net. 2007; 103: 30-31.

[18] Polzer Casarez RL, Engebretsen JC. Ethical issues of incorporating spiritual care into clinical practice. Journal of Clinical Nursing. 2012; 21: 2099-2107. PMid:22788552 http://dx.doi.org/10.1111/j.1365-2702.2012.04168.x

[19] Gadamer H-G. Wahrheit und Metode. Translation to English and revised by Weinsheimer J, and Marshall DG, (1989). Second revised edition. London: Sheed \& Ward; 1960. 
[20] Selbæk G, Kirkevold Ø, Engedal K. The prevalence of psychiatric symptoms and behavioural disturbances and the use of psychotropic drugs in Norwegian nursing homes. International Journal of Geriatric Psychiatry. 2007; 22: 843-849. PMid:17193341 http://dx.doi.org/10.1002/gps.1749

[21] Kvale S. Det kvalitative forskningsintervju (The qualitative research interview). Oslo: Ad Notam Gyldendal; 1997.

[22] Wikström B-M. Seniors’ Experiences of Congregate Housing in Sweden. Journal of Creative Nursing. 2010; 16 : 87-94. http://dx.doi.org/10.1891/1078-4535.16.2.87

[23] Gallagher A. Dignity and respect for dignity - two key health professional values: implications for nursing practice. Nursing Ethics. 2004; 11: 587-99. PMid:15597939 http://dx.doi.org/10.1191/0969733004ne7440a

[24] Caspari S. Eksistensiell lidelse og smerte (Existential suffering and pain). In A. Aambø (Ed.), Smerte: smerteopplevelser og atferd (Pain: pain experiences and behaviour). Oslo: Cappelen Forlag; 2007: p. 74-78.

[25] Ulrich R. Effects of facility interior design on wellness. Theory and recent scientific research. Journal of Health Care and Interior. 1991; 3: 97-109.

[26] Ulrich RS. Effects of Healthcare Environmental Design on Medical Outcomes. In Dilani A, (Ed.) Design \& Health. Stockholm: Svensk Byggtjänst. 2001: p. 49-60.

[27] Kant I. Grundlegung zur Metaphysik der Sitten (Morallov og Frihet). Translated to Norwegian, and selections by Storheim E, (1970). Gjøvik: Gyldendal Norsk Forlag A/S; 1785.

[28] Bible. King David Psalm 142, verse 1-5. Oslo: Det Norske Bibelselskap Forlag. 1953. 